\title{
PECULIARITIES OF WELDING AND CONTROL IN MANUFACTURE OF HEAT-EXCHANGE MODULES OF EXHAUST-HEAT BOILER OF STEAM-GAS ELECTRIC PLANT OF 150 MW CAPACITY
}

\author{
A.K. TSARYUK ${ }^{1}$, V.P. ELAGIN ${ }^{1}$, E.A. DAVYDOV ${ }^{1}$, A.R. GAVRIK ${ }^{1}$, A.I. PASECHNIK ${ }^{2}$, \\ S.A. POLONETS ${ }^{2}$, V.G. DEDOV ${ }^{3}$ and V.P. GORELOV ${ }^{3}$ \\ ${ }^{1}$ E.O. Paton Electric Welding Institute, NASU \\ 11 Bozhenko Str., 03680, Kiev, Ukraine. E-mail: office@paton.kiev.ua \\ 2 «Donetskenergoremont» Ltd \\ 1 Umov Str., 83008, Donetsk, Ukraine. E-mail: postmaster@er/donetsk/ua \\ ${ }^{3}$ Company «Alchevsk Iron \& Steel Works» \\ 4 Shmidt Str., 94202, Alchevsk, Lugansk region, Ukraine. E-mail: amk@amk.lg.ua
}

\begin{abstract}
Manufacture of exhaust-heat boiler of steam-gas plant of 150 MW capacity for Alchevsk Iron \& Steel Works allowed using the secondary metallurgical gases as alternative to the nature gas. Its modular design, high closeness of arrangement in heat-exchange blocks of thin-walled small-diameter pipes of heating surfaces decreased the dimensions of the plant and increased its efficiency factor up to $44.6 \%$. Due to a narrow gap between the pipes the butts of these pipes occurred to be hard-to-reach for welding and control. This caused the increase in the amount of inadmissible defects in welds, and also made the welded joints of pipes almost not suitable for the repair. The making of welded joints on different stands by applying methods of argon-arc and combined welding allowed improving the quality, gave an opportunity to perform repair and to realize their X-ray, ultrasonic and visual-optic control. The manufactured heat-exchange blocks withstood the hydraulic test without appearance of leakage in welded joints, were installed and put into service. 3 Ref., 1 Table, 5 Figures.
\end{abstract}

Keywords: secondary gas fuels, steam-gas plant, heat-exchange blocks, piping of heating surfaces, header, arc welding, quality control

Significant saving of fuel for industrial enterprises of the metallurgical industry is the application of secondary fuel gases, such as blast furnace, converter, coke gases, forming during the metallurgical processes. Their application as a fuel, alternative to natural gases, was feasible by using steam-gas plants (SGP) of a combination cycle. In these plants the gases are mixed to form the safe concentration and required heat-generating ability and are burnt out, and the generated heat is converted into mechanical and electric energy. At Alchevsk Iron \& Steel Works (AMK) a complex of SGP of total power of $300 \mathrm{MW}$ (two blocks of $150 \mathrm{MW}$ ) was manufactured. The designing of SGP was made by the Mitsubishi Heavy Industries Company (Japan) with participation of Industrial Union of Donbass [1]. Construction of steam-gas electric plant for utilization of blast furnace, converter and coke gases (similar to AMK) was planning at F.E. Dzerzhinsky Dneprovsky Iron \& Steel Works. The Iron \& Steel Works «Azovstal» also announced about implementation of two SGP [2]. At AMK the operation of two steam-gas blocks allows providing the almost full need in electric power, keeping the standards for harmful gas blow-outs, accepted in EU.

One of the SGP main components is an exhaust-heat boiler, which was designed from heatexchange modules of the evaporator, steam superheater and economizer.

The heat-exchange modules were assembled of header panels, each of them has inlet and outlet headers (Figure 1, $a, b$ ) with three rows of $A, B$ and $C$ holes on the lateral surface, in total $40 \mathrm{pcs}$ in each one (Figure 2, $a$ ). Concentrically to these holes the connecting pipes are welded-on by fillet weld, which in turn are joined by butt weld to pipes of heating surfaces (Figure 2, $b$ ). The fillet joints of connecting pipes and butt joints of pipes of heating surfaces were made with a full penetration. Connecting pipes in the middle and edge row were bent at 25 and $50^{\circ}$ angle, respectively. Diameter of pipes and connecting pipes is 31.8 , 38.1 and $50.8 \mathrm{~mm}$, depending of panel purpose, however, their wall thickness is similar $2.7 \mathrm{~mm}$. 


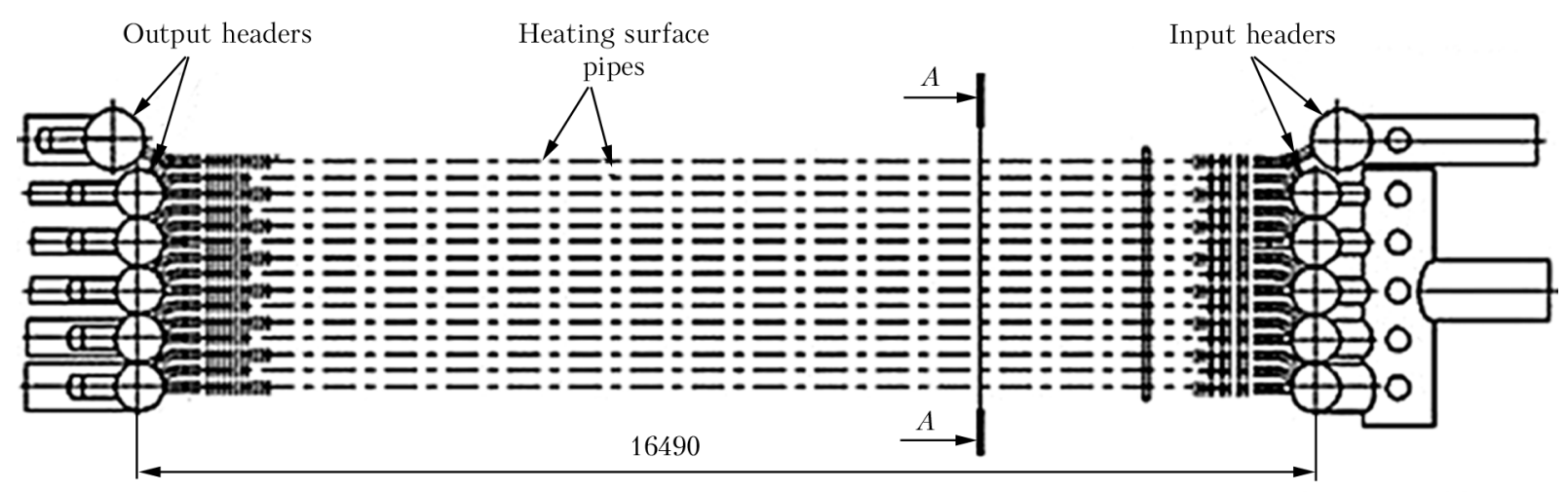

$A-A$
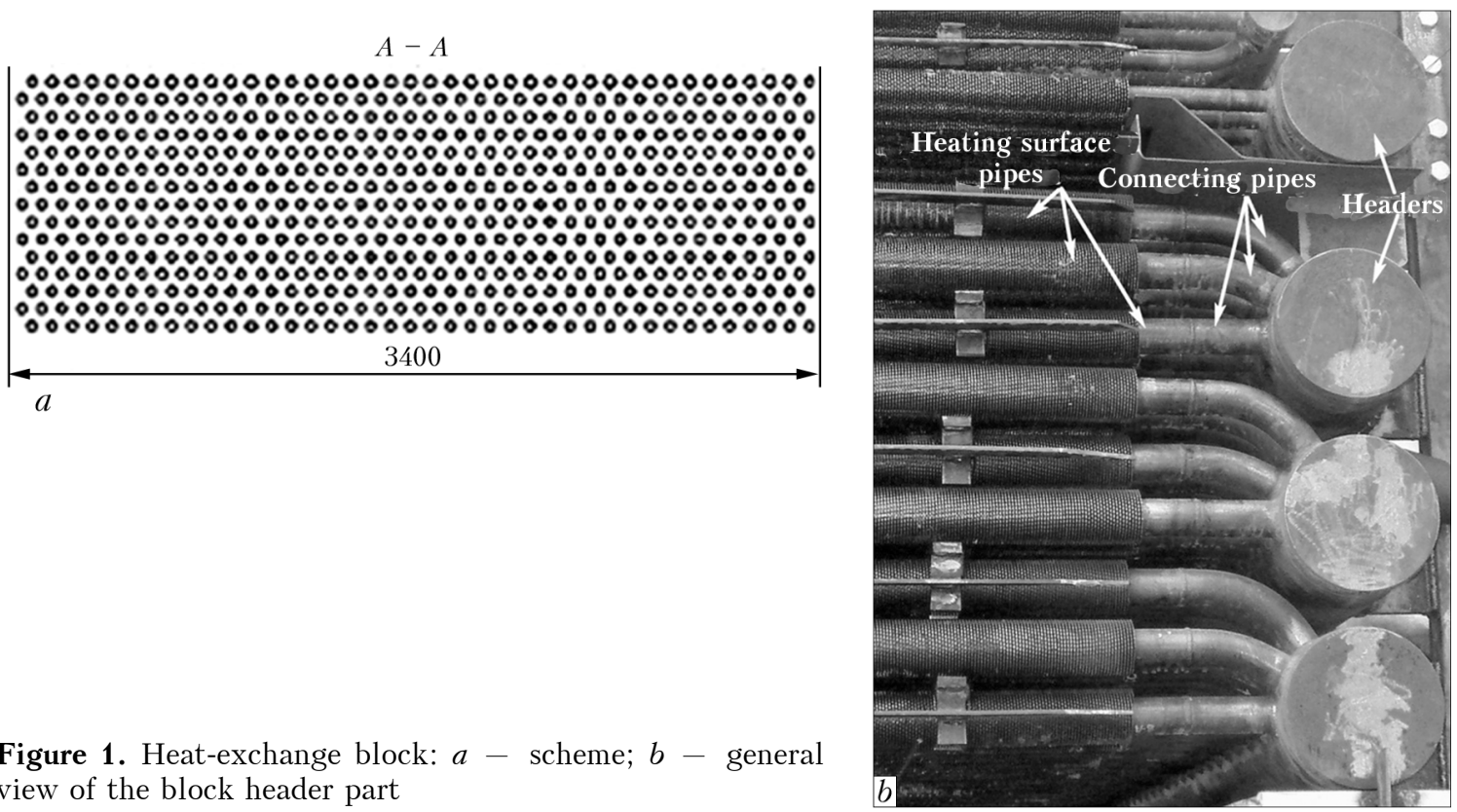

Figure 1. Heat-exchange block: $a-$ scheme; $b-$ general view of the block header part

As pipes of heating surfaces the finned pipes of ASME standard of steel SA 192 (analog to steel 20) and steel SA 213T11 (analog to steel $15 \mathrm{KhM}$ ) (the Table) are used for service at temperatures up to $300{ }^{\circ} \mathrm{C}$ and higher, respectively. Casings of header are made of pipes of steels 20 and $12 \mathrm{Kh} 1 \mathrm{MF}$ (see the Table) (TU 14-3-460 and TU 14-3R-55) of 219, 220, $240 \mathrm{~mm}$ diameter with 9, 15 and $22 \mathrm{~mm}$ wall thickness, respectively.

Application of bent connecting pipes allowed decreasing greatly a gap (to $15 \mathrm{~mm}$ ) between fins of pipes of heating surfaces, increasing the number of pipes in block up to $600 \mathrm{pcs}$, and closeness of their arrangement in pipe bundle up to $250 \mathrm{pcs} / \mathrm{m}^{2}$. This contributed to increase in the efficiency factor of the plant up to $44.6 \%$ and decrease in its dimensions.

These peculiarities of the block design hinder greatly the access to butts of edge rows of pipes in welding and repair and make it almost impossible for connections of internal rows of the block piping. This predetermined the high requirements to welding and methods of control for each joint, avoiding the need in repair of its defects after manufacture of panels and block.
The main principles of technology of welding
of pipes of heating surfaces were defined by the standard document [3]. However, it has no recommendations for welding of panels and blocks with high closeness of arrangement of pipes of heating surfaces, the butt and fillet welded joints of which were made with a complete penetration.

The present work was aimed at optimizing the technology of welding the heat-exchange panels with account for peculiarities of their design.

Decisive in providing the high quality is the development of optimum variant of sequence of making the welded joint, which will provide the best access to the butt areas. Two main variants are possible:

1. Firstly the fillet joints are made for connecting pipes with inlet and outlet headers, and then - butt joints of these connecting pipes with pipe of heating surface. After manufacture of the panel the assembly and welding of next panel is made from the top and so on up to manufacture of the whole block. Moreover, the works on assembly, welding and quality control of panels and the block as a whole are performed on the same stand. 


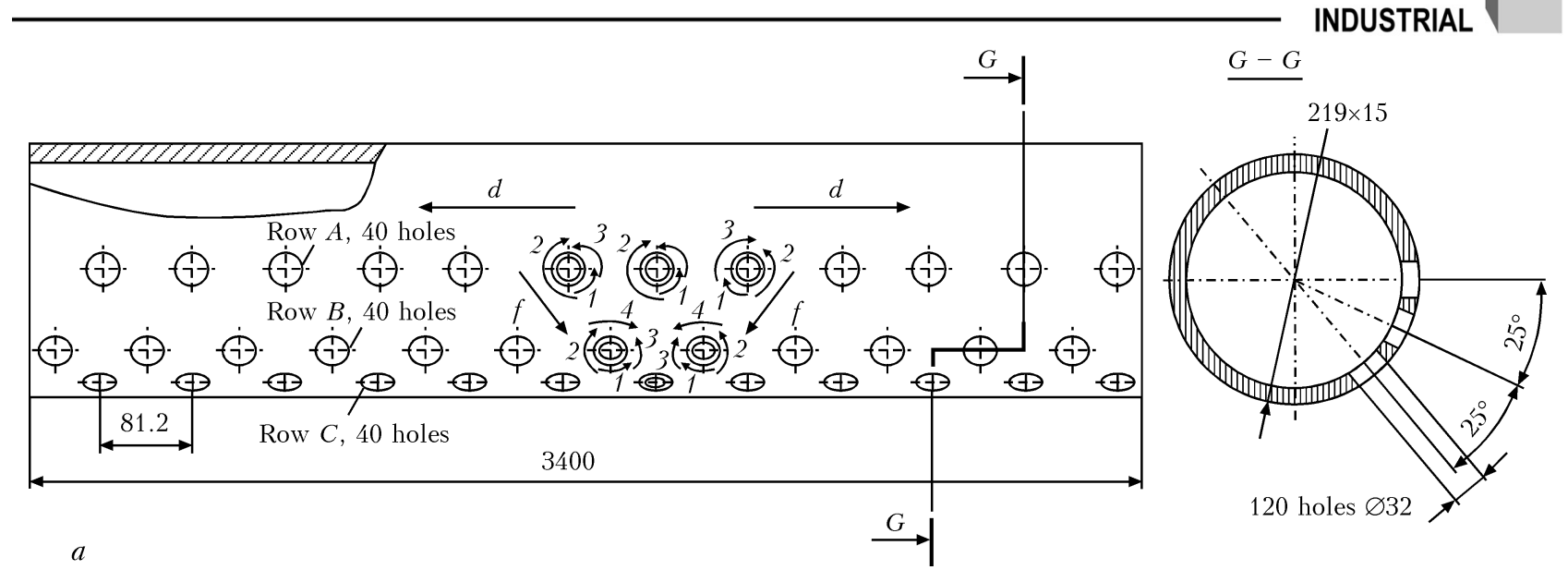

2. Firstly the butt joints are made for connecting pipes with pipe of heating surface with formation of so called «pipe section», and then the fillet welds of «pipe section» with inlet and outlet headers are made. Moreover, the works on welding and quality control are performed on two stands: stand for assembly and welding of butt joints of connecting pipes with heat-exchange pipe, and stand for assembly and welding of heat-exchange pipe with header.

The second variant as compared with the first one requires almost 2 times more industrial area and the presence of high-load capacity cranes for transfer of panels in assembly of heat-exchange blocks.

The technology of welding was optimized on model headers, design of which provided the same difficult access to weld areas, as in a real product. Weld of butt joints of specimens were made in two layers by argon arc welding with tungsten electrode using filler wire (TIG), and fillet welds were made in three layers by TIG welding or manual arc welding with covered electrodes (MAW). The combined method of welding of fillet weld, at which a root weld was made by TIG welding, and the rest ones - by MAW, was also tested. The quality of welding was evaluated by visual-optic, ultrasonic or radiographic methods of control, and metallographic examinations by optic microscope were also carried out.

During welding according to the first variant the hard-to-reach places are areas 1, 3 and 4 both of butt and also fillet weld. During works fulfillment according to the second variant the hardto-reach places are only areas 4 of fillet welds. Welding in the direction of arrows $d$ and $f(\mathrm{Fi}-$ gure $2, a$ ) makes the welding of the area 1 , located in overhead position of weld, more convenient.

At the hard-to-reach areas of butt the visualization of welding zone and its process are rather difficult. At violation of welding procedure the gas shielding of welding zone, formation of weld

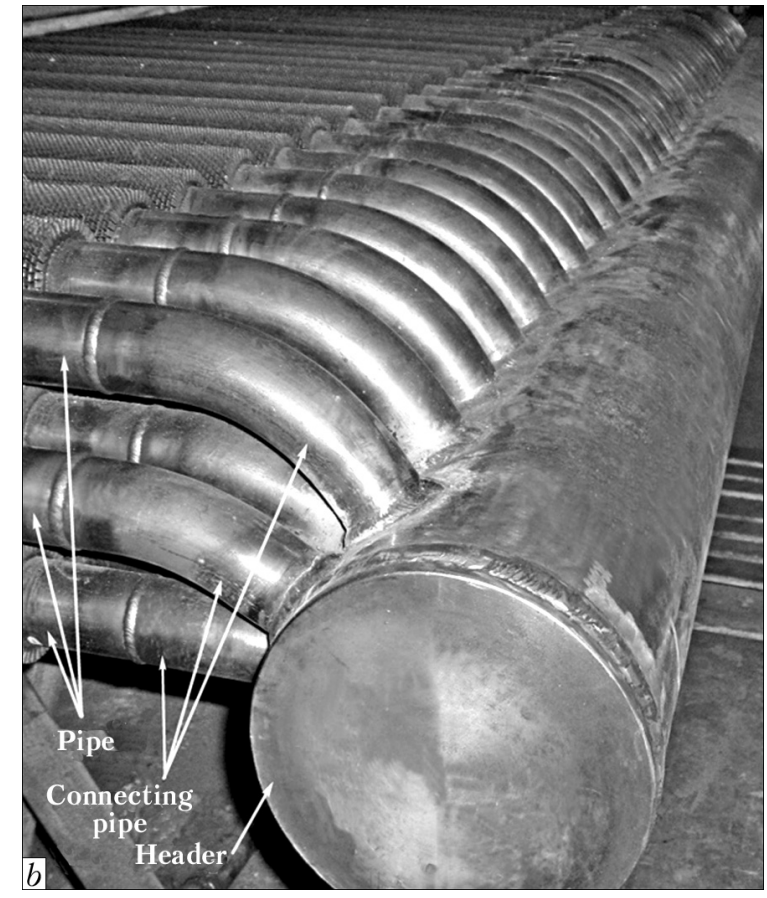

Figure 2. Header unit of heat-exchange panel: $a-$ scheme of arrangement of connecting pipes on header (1-4 - sequence of welding of weld areas; $b-$ general view of header unit; arrows show sequence of welding-on of connecting pipes)

are deteriorated that leads to the formation of pores. The most sensitive to the pores are butt joints due to low energy input of their welding as compared with the fillet welds and also due to lower silicon content in pipe metal than in header metal (see the Table). The percentage of rejection of butt joints due to formation of pores in welds during TIG welding according to the first variant reached up to $40 \%$.

During MAW the joining of hard-to-reach weld areas becomes much easier and resistance to pore formation is increased, however, the inadmissible metal sagging and slag overlaps are formed in the weld root layer. Therefore this method cannot be applied for welding of small-diameter pipes with a complete penetration. 
INDUSTRIAL

Chemical composition of pipe metal, \%

\begin{tabular}{|c|c|c|c|c|c|c|c|c|}
\hline Steel grade, standard & $\mathrm{C}$ & $\mathrm{Si}$ & Mn & $\mathrm{P}$ & $\mathrm{S}$ & $\mathrm{Cr}$ & Mo & $\mathrm{V}$ \\
\hline SA 192, ASME & $0.06-0.18$ & $\leq 0.25$ & $0.27-0.63$ & $\leq 0.035$ & $\leq 0.035$ & - & - & - \\
\hline $\begin{array}{l}\text { Protocol of steel analysis } \\
\text { SA } 192\end{array}$ & 0.097 & 0.17 & 0.45 & 0.007 & 0.003 & - & - & - \\
\hline SA 213T11, ASME & $0.05-0.15$ & $0.5-1.0$ & $0.30-0.60$ & $\leq 0.025$ & $\leq 0.025$ & $1.0-1.5$ & $0.44-0.65$ & - \\
\hline $\begin{array}{l}\text { Protocol of steel analysis } \\
\text { SA } 213 T 11\end{array}$ & 0.11 & 0.58 & 0.48 & 0.005 & 0.002 & 1.22 & 0.56 & - \\
\hline Steel 20, GOST 8731-87 & $0.17-0.24$ & $0.17-0.37$ & $0.35-0.65$ & $\leq 0.035$ & $\leq 0.040$ & $\leq 0.3$ & - & - \\
\hline Protocol of steel 20 analysis & 0.17 & 0.36 & 0.55 & 0.032 & 0.038 & 0.1 & - & - \\
\hline 12Kh1MF, GOST 1133-71 & $0.08-0.15$ & $0.17-0.37$ & $0.40-0.70$ & $\leq 0.030$ & $\leq 0.025$ & $0.9-1.2$ & $0.25-0.35$ & $0.15-0.30$ \\
\hline $\begin{array}{l}\text { Protocol of } 12 \mathrm{Kh} 1 \mathrm{MF} \text { steel } \\
\text { analysis }\end{array}$ & 0.09 & 0.33 & 0.62 & 0.028 & 0.022 & 1.1 & 0.32 & 0.18 \\
\hline 15KhM, GOST 8732-78 & $0.11-0.18$ & $0.17-0.37$ & $0.4-0.7$ & $\leq 0.035$ & $\leq 0.035$ & $0.8-1.1$ & $0.40-0.55$ & - \\
\hline $\begin{array}{l}\text { Protocol of } 15 \text { KhM steel } \\
\text { analysis }\end{array}$ & 0.12 & 0.35 & 0.58 & 0.030 & 0.032 & 0.096 & 0.48 & - \\
\hline
\end{tabular}

During fulfillment of works according to the second variants, assembly and welding of pipes with a connecting pipe on the separate stand ( $\mathrm{Fi}-$ gure $3, a$ ) was made. Its design provides an accuracy and rigidity of assembly of butt, and also free access to all its areas. The possibility of fulfillment of the required procedure of welding allows increasing the safety of gas shielding of welding and improving the formation of finishing and root layer (Figure $4, a, b$ ). Percentage of
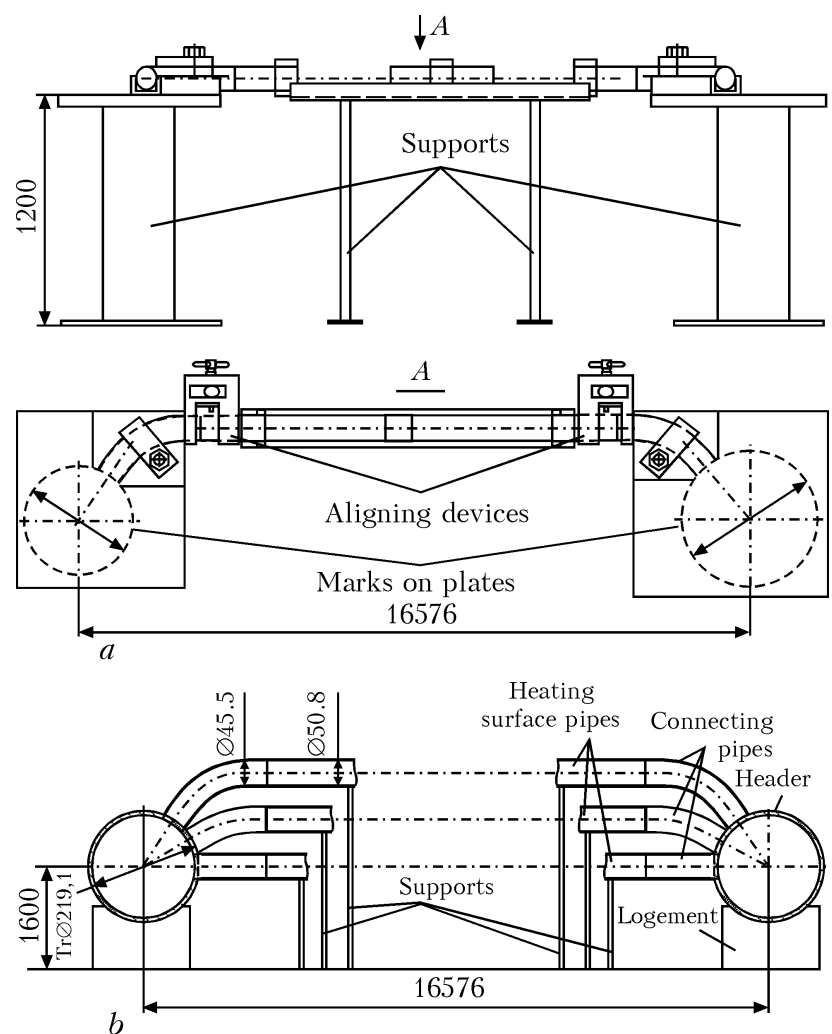

Figure 3. Stands for assembly and welding of butt joints of pipes of heating surfaces with connecting pipes $(a)$ and of fillet joints of header with «pipe section» $(b)$ defective welds due to pore formation was reduced to $0.4 \%$.

Assembly and welding of fillet joint of header with «pipe section» are made on the second stand (Figure 3,b) after checking the quality of butt joint of pipe and connecting pipe. Accuracy of assembly is provided by means of devices.

In TIG welding of fillet weld the pores are more often occur at the 4th region (see Figure 2, a) of the third layer adjacent to the connecting pipe. In the root and the second layer, deposited on header, pores are formed. This can be explained by increased silicon content in these layers, transferred from the base metal of header, in which its content is more than 2 times higher than in pipe metal (see the Table).

In MAW the pores in layers of the fillet weld were not revealed. High resistance against the pores at this method is explained by the more safe gas-slag protection of the welding zone than in TIG welding. In this connection, it is recommended to perform welding of fillet weld by the combined method: root layer by TIG welding and next layers by MAW.

The small diameter of covered electrode for MAW as compared to sizes of torch for TIG welding allows making welding without any problems in hard-to-reach areas, providing the safe shielding of the welding zone. During welding in the upward direction the often occurred defects of the fillet joint are a sharp transition from deposited metal surface to the surface of connecting pipe and formation of slagging at the «locks» area. The downward welding allows improving the shape of the fillet weld even at low skill of the welder, however, the probability of formation of lacks of fusion and slagging in the lower 

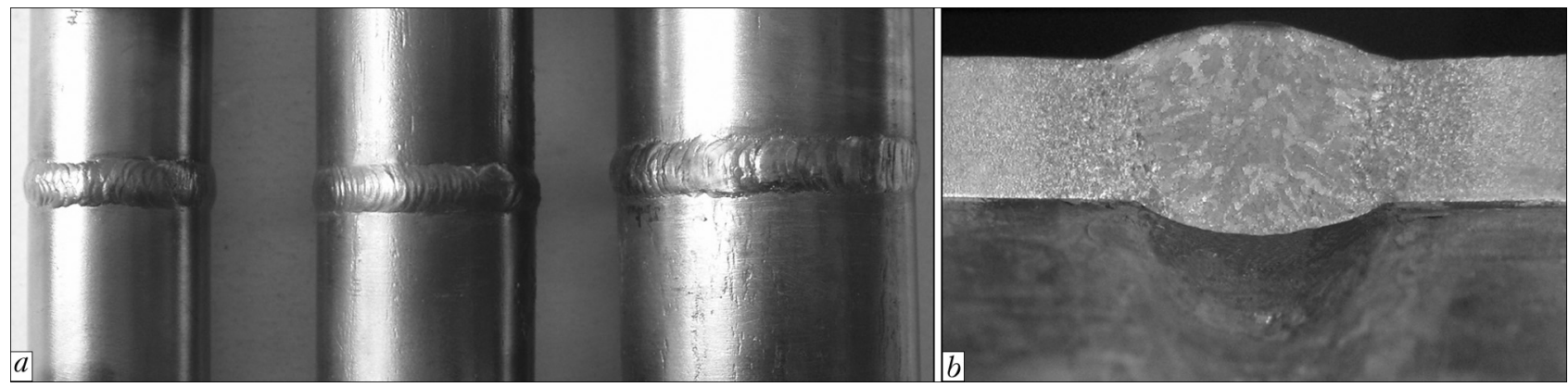

Figure 4. Butt joints of heating surface pipes: $a-$ appearance of joints; $b-$ transverse section of joint

part of the weld is increased. To prevent them the application of special electrodes is required. As there are no such electrodes at the market, the E.O. Paton Electric Welding Institute has started their development. To make upward welding of fillet welds of pipes of heating surfaces of steels SA 192 and SA 213T11 the most suitable are the electrodes TsU-5 and TsL-39 by their welding-technological properties, respectively. They allow producing the quality formation with the higher properties than that of the base metal.

One more type of occurred defects of fillet welds, made by the combined method, are pores and shrinkages in the root bead (Figure 5, a). They are formed in the hard-to-reach areas of the third layer of the weld in case of complete penetration of the connecting pipe wall. At the absence of the gas shielding of root bead the molten metal is saturated with gases, thus leading to the formation of pores, and the oxidized surface of metal deteriorates the formation of root part of penetration and causes the formation of shrinkages. The blowing-in of argon into the pipe in the butt area prevents completely the formation of such defects (Figure 5, b). In this case the reduction in argon consumption to $31 / \mathrm{min}$ is attained by using limiting collars, placed into pipe on both sides from the butt.

The making of welded joints to join the connecting pipe with heating surface pipe according to the second variant on the separate stand allows the X-ray control to be performed in the separate room. This makes its fulfillment more safe without interruption of other works. The feasibility is also appeared in an additional control of integrity of weld metal of butt joints by the ultrasonic method and quality of formation of weld root bead using video endoscope. The $100 \%$ visual-optic, X-ray and $10 \%$ ultrasonic testing could improve greatly the validity of their results. The volume of rejection in butt joints made in welding according to the first and second variants, was 40 and $0.5 \%$, respectively.
The fillet welds of connecting pipe to header are more difficult for the revealing of defects. Their design makes it impossible to apply the X-ray control, dye penetrant or magnetic powder flaw detection. In this connection the procedures of ultrasonic testing of integrity of fillet weld and visual-optic control of quality of the root bead formation were developed.

To improve the validity of results of the ultrasonic testing, the adaptation of parameters of the ultrasonic channel was made for peculiarities of fillet joints of thin-walled small-diameter pipes and chord transducers were applied. Small

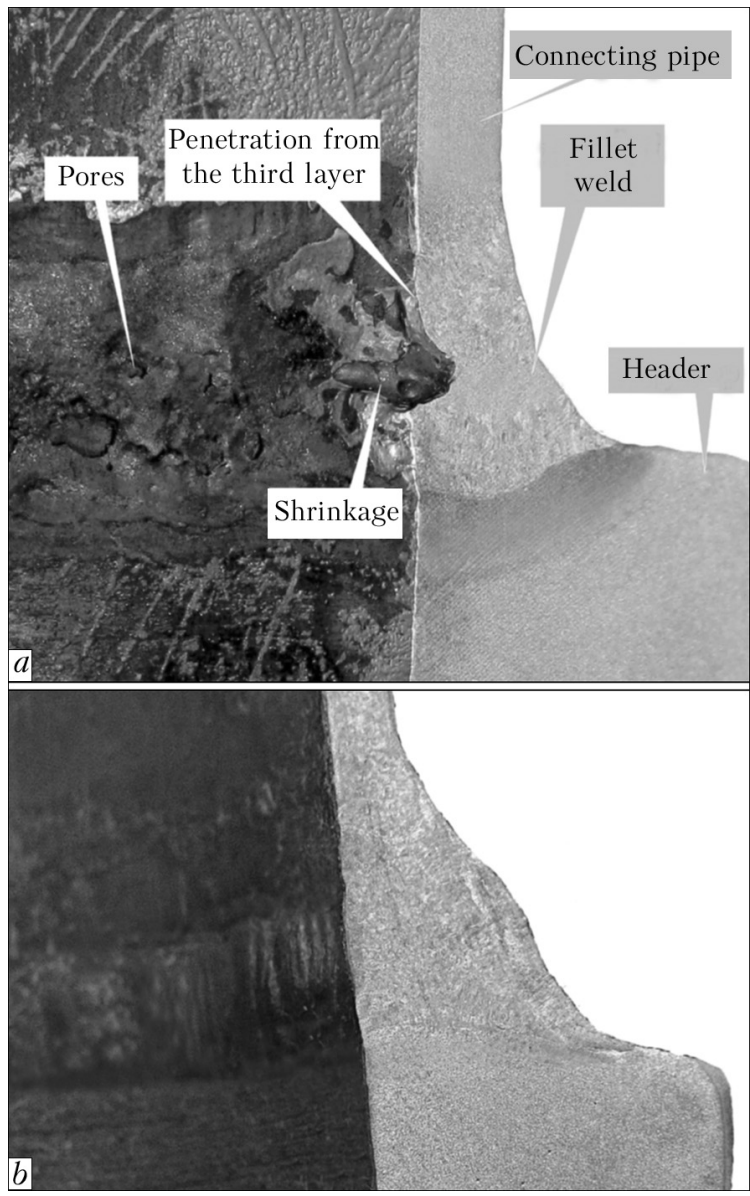

Figure 5. Fillet welded joints of connecting pipe with header: $a$ - transverse section of joint with defects in root bead made without argon blowing-in; $b-$ transverse section of joint made with argon blowing-in 
sizes of the transducers (height $\leq 20 \mathrm{~mm}$, width of $18 \mathrm{~mm}$ ) make it possible to control the welds in hard-to-reach areas of welded joints, and an elastic protector provides a stable acoustic contact. They are especially effective in revealing the volume defects, such as channel pores (flaws), slags, pores and flat defects, cracks, lacks of penetration and lacks of fusions.

The feasibility of control of the root bead formation of both butt and also fillet welds was obtained due to application of the modern model of the endoscope. It has the flexible probe of $6 \mathrm{~mm}$ diameter and length of up to $3.5 \mathrm{~m}$ with the light guide and small-sized optic head at vision angle up to $120^{\circ}$. The unit allows changing the depth resolution and direction of examination, making visualization of examining area on the monitor and photo-video recording of examination results into the flash-map memory. When pores in the root bead, inadmissible sagging or shrinkages in joint areas were revealed, the joints were rewelded before fulfillment of joints of next pipes which close the welding zone. In addition, the foreign objects, for example paper, electrode stubs, chips, etc., which should be obligatory removed, were revealed inside pipes and header by using the endoscope.

Thus, the fulfillment of works according to the second variant of assembly and welding of panels of heat-exchange blocks allows more qualitatively performing both butt, and also fillet joints, realizing control of their quality within $100 \%$ volume and repairing of the defective welds. The carried out production certification of technology of welding showed that joints are equal by their strength to the base metal. The manufactured heat-exchange blocks have passed successfully the leakage tests by hydraulic testing and were installed in exhaust-heat boilers of the steam-gas electric plant of $150 \mathrm{MW}$ capacity at Alchevsk Iron \& Steel Works.

\section{Conclusions}

1. Heat-exchange blocks of modules of exhaustheat boiler of $150 \mathrm{MW}$ SGP have a high closeness of arrangement of thin-walled pipes of heating surfaces. During welding and assembly of heat- exchange blocks on one stand this peculiarity of design makes the butt and fillet joints of these pipes as hard-to-reach ones for fulfillment of welding and control, promotes the increased defect formation and leads to impossibility for their repair after welding.

2. The most frequently occurred defects in welds of butt joints made by TIG welding are pores, and a sharp transition from weld surface to connecting pipe surface, slagging on «locks», pores and shrinkages in the root bead are typical of fillet joints made by the combined method. These defects are formed, as a rule, in hard-toweld areas in MAW and are repaired by technological methods, improvement of skill and experience of the welder.

3. The most effective technological method of improvement of quality of welds of butt and fillet joints of pipes of heating surfaces is the fulfillment of their assembly and welding on separate stands, providing the more free access to butts in welding and feasibility of repair and control of their quality in $100 \%$ volume.

4. Increase of resistance against formation of pores and shrinkages in root bead of fillet welds of pipe surfaces is attained by a gas shielding of root bead using argon blowing-in inside the pipe.

5 . To improve the validity of the quality control of butt and fillet welded joints, the procedures of ultrasonic and visual-optic control by using the chord transducers and endoscope were applied respectively.

1. Falkov, M.I. (2007) Increase in power efficiency of application of by-product fuels on iron industry enterprises. Electron journal EXPO of power service company «Ecological systems», 6. http://Www. esco-ecosys.narod.ru /2007_6/art103/.thm

2. Fomina, O. (2014) Application of blast-furnace, converter, coke gases in combined-cycle plants contribute to reduce electric power consumption of national power network on metallurgical works. http://masters.donntu.org / 2011/feht/tovshchik/library/arti cle7.htm

3. RTM-1s-89: Guiding technical document. Welding, heat treatment and control of pipe systems of boilers and pipelines in erection and repair of power plant equipment. Moscow: NPO OBT.

Received 20.11.2014 